\title{
LEVANTAMENTO SOCIOECONÔMICO E AMBIENTAL VOLTADO PARA A IMPLEMENTAÇÃO DE POLÍTICAS PÚBLICAS NO BAIRRO MORRO DO ALGODÃO, CARAGUATATUBA (SP)
}

\author{
Aécio Givanildo de Sousa Braz ${ }^{1}$ \\ Renato Amaro Zângaro²
}

Resumo: O crescimento desordenado do espaço urbano traz consequências nefastas ao meio ambiente e ao exercício pleno da cidadania. Logo, um diagnóstico socioambiental torna-se uma importante ferramenta para auxiliar o poder público na tomada de decisões. Este trabalho visou obter e analisar dados socioeconômicos e ambientais de um bairro situado na periferia de Caraguatatuba, Litoral Norte do estado de São Paulo, por meio de um questionário semiestruturado aplicado a 113 alunos de uma escola pública local. O saneamento básico está entre os principais problemas encontrados. $O$ quadro socioambiental obtido visa promover sua divulgação junto aos setores públicos e privados que podem interferir nesse tecido social.

Palavras-chave: Urbanização; Políticas Públicas; Levantamento Socioeconômico e Ambiental.

${ }^{1}$ Universidade de Camilo Castelo Branco. E-mail: braz_geomsb@hotmail.com

${ }^{2}$ Universidade Camilo Castelo Branco. E-mail: razangaro@gmail.com.

Revbea, São Paulo, V.10, № 2: 58-72, 2015. 


\title{
Introdução
}

O processo de urbanização no Brasil ocorreu tardiamente, impulsionado por uma industrialização que desencadeou um intenso êxodo rural, forçando milhões de brasileiros a migrarem para as cidades. Contudo, o espaço urbano não absorveu toda a mão-de-obra oriunda do campo. Este fato resultou em largo desemprego que associado à especulação imobiliária fez surgir um dos grandes problemas das cidades que é o direito a moradia. Esta é apenas uma dentre inúmeras adversidades causadas quando a cidade cresce de modo desordenado, como ocorre em maior ou menor grau em muitas cidades brasileiras, as quais possuem sérios dilemas socioeconômicos, podendo ser exemplificado pela favelização e exclusão social, saneamento, saúde e mobilidade precária, até o adoecimento do ambiente físico, como poluição das águas, da atmosfera e os desmatamentos, que impactam diretamente na qualidade de vida e comprometem o direito do exercício da plena cidadania.

Neste sentido, a cidade, está fadada a ser tanto o teatro de conflitos crescentes como o lugar geográfico e político da possibilidade de soluções, como aponta Santos (2005). Portanto, para amenizar estes conflitos é que a criação de políticas públicas torna-se fundamental, no intuito de promover um crescimento urbano equilibrado nas questões sociais, econômicas e principalmente ambientais de um território.

Num estudo que analisa criteriosamente o conceito de políticas públicas, Souza (2006, p.23), reúne algumas citações de importantes teóricos e afirma que não existe uma única, nem melhor definição sobre o que seja política pública e descreve que:

\begin{abstract}
Mead (1995) a define como um campo dentro do estudo da política que analisa o governo à luz de grandes questões públicas e Lynn (1980), como um conjunto de ações do governo que irão produzir efeitos específicos. Peters (1986) segue o mesmo veio: política pública é a soma das atividades dos governos, que agem diretamente ou através de delegação, e que influenciam a vida dos cidadãos. Dye (1984) sintetiza a definição de política pública como "o que o governo escolhe fazer ou não fazer". A definição mais conhecida continua sendo a de Laswell, ou seja, decisões e análises sobre política pública implicam responder às seguintes questões: quem ganha o quê, por quê, e, que diferença faz.
\end{abstract}

Políticas públicas se realizam a partir de um diagnóstico prévio sobre a realidade à qual será impactada, e é dessa maneira que este estudo ganha relevância, ao buscar conhecer e levantar dados socioeconômicos e ambientais de um bairro periférico de Caraguatatuba. Para se conhecer a realidade de uma localidade, nos seus aspectos sociais, culturais, econômicos 
e ambientais e como estes elementos se relacionam, é indispensável fazer um levantamento de dados, no intuito de identificar os problemas recorrentes pelo qual passa essa população e seu espaço geográfico, e a partir daí, propor ações viáveis.

A Lei Federal 6938 de 31 de agosto de 1981, da Política Nacional de Meio Ambiente, no artigo 6º , citado por Hunka (2006), denomina o diagnóstico ambiental como uma descrição e análise dos recursos ambientais e suas relações caracterizando a situação ambiental da área, mas também considera além do meio físico, o meio socioeconômico e as suas relações no espaço e a utilização futura dos recursos naturais ali presentes. É oportuno salientar que os aspectos sociais são inerentes ao se analisar as relações ambientais, porque a sociedade ao mesmo tempo em que modifica o espaço, sofre as consequências dessa ação.

De acordo com (AGRA FILHO, 1993) apud Hunka (2006), num diagnóstico socioambiental, um dos objetivos é interpretar a realidade das condições ambientais, identificando a dinâmica dos processos que interferem na sua qualidade.

Complementando este conceito, Alves e Leal (2003), afirmam que o momento de se fazer o diagnóstico ambiental permite avaliar os principais problemas e as perspectivas de soluções, que darão apoio aos planos de trabalho e as propostas de ações futuras no local. O mesmo autor ainda diz que se trata de um trabalho complexo e que depende da capacidade de percepção, observação, interpretação e sistematização dos vários processos sociais e naturais presentes.

Situado no Litoral Norte de São Paulo, o município de Caraguatatuba é circundado pela Mata Atlântica, considerado um dos mais ricos e ameaçados biomas do Brasil, que por sinal sofre também com o vertiginoso crescimento urbano. Sua urbanização ganhou força a partir da construção da rodovia dos Tamoios (SP 99) na década de 1950, e acelerou-se a partir de sua reforma e pavimentação na década de 1970. Nesse período Caraguatatuba passou a receber grande fluxo de imigrantes e proprietários de casas de veraneio. Atualmente a cidade vive um paradoxo, possui cerca de $40 \%$ das suas casas fechadas, enquanto os bairros periféricos crescem de modo rápido e precário, como é o caso do bairro Morro do Algodão.

Gigliotti e Santos (2013) descrevem que a malha urbana passa a caracterizar a dinâmica do município, com $95 \%$ da população fixada no espaço urbano, formada por moradores locais e imigrantes que foram atraídos pelas oportunidades desencadeadas pelo turismo, mas que não foram absorvidos pelo mercado da região e que passaram a compor um segmento marginalizado, fixando moradia em áreas mais afastadas da cidade, no qual hoje são os bairros mais carentes e sem infraestrutura.

No Morro do Algodão, área de estudo delimitada neste trabalho, há 
indispensáveis para o exercício da cidadania, além de conviver e potencializar os problemas ambientais, comprometendo sua qualidade de vida e o equilíbrio ambiental.

O presente trabalho teve como objetivo obter $\mathrm{e}$ analisar dados socioeconômicos e ambientais relevantes do bairro Morro do Algodão com o intuito de diagnosticar a realidade do bairro, identificando os principais problemas ambientais e fornecer subsídios para a implementação de futuras políticas públicas.

\section{Material e Método}

Por se tratar de uma pesquisa envolvendo seres humanos, que responderam ao questionário, foi necessário submeter o projeto ao Comitê de Ética em Pesquisa (CEP), que o aprovou sob o número do CAEE 40927114.7.0000.5494.

Santos (2009), afirma que o estudo socioambiental de um determinado espaço, deve ter, além de seus métodos de análise técnica, a participação dos envolvidos. Logo, o uso de questionários pode se tornar uma ferramenta que auxilia e facilita a identificação dos problemas e a relação sociedade-espaço, ainda mais pelo fato de que o caráter desta pesquisa quantitativa tem como objetivo a coleta de dados primários.

O procedimento metodológico deste artigo visou obter dados do bairro Morro do Algodão por meio de um questionário socioeconômico e ambiental semiestruturado. $O$ mesmo foi aplicado a 113 alunos com faixa etária entre 13 e 15 anos, cursando o $9^{\circ}$ ano do Ensino Fundamental II e $1^{\circ}$ ano do Ensino Médio. A Unidade Escolar escolhida para a coleta dos dados foi a Escola Estadual Prof. a Maria Ester das Neves Dutra Damásio, situada no bairro supracitado. Como critério de inclusão, para participar do estudo, os entrevistados deviam ser moradores do bairro.

A elaboração do questionário foi baseada a partir de um trabalho de campo realizado por Baldin et al. (2004). Os questionamentos tiveram caráter quantitativo e análise qualitativa. A aplicação ocorreu após preenchimento de TCLE (Termo de Consentimento Livre Esclarecido) e da instrução do pesquisador aos alunos entrevistados. Foi fornecido um questionário para cada aluno, com 40 questões para serem respondidas: uma parte em sala de aula e outra em suas residências. É importante salientar que determinadas questões requeriam o auxílio dos responsáveis, como exemplo: a renda familiar e questões sobre saneamento.

Após-aplicação do questionário foi feita a tabulação de dados para verificar o percentual das respostas e geração de gráficos (autoria própria) para melhor visualização dos resultados, obtidos com o software Microsoft Excel. Em seguida, os resultados foram analisados e discutidos. 


\section{Resultados e Discussão}

A análise dos resultados obtidos através do questionário foi subdividida em três temáticas, a saber: comunicação e cultura; infraestrutura/aspectos socioeconômicos; saneamento básico/meio ambiente.

\section{Aspectos culturais e meios de comunicação}

De um total de 113 entrevistados, 54\% pertenciam ao sexo feminino. Em relação à origem, $43 \%$ não nasceram no município, fator indicativo de uma forte imigração ocorrida desde 1960. Panizza (2004) destaca que o município de Caraguatatuba teve grande crescimento populacional entre 1960 e 1970, principalmente após as ligações rodoviárias com as cidades do Vale do Paraíba, assim como os investimentos no setor imobiliário, nas atividades do Porto de São Sebastião e na criação do TEBAR (Terminal Marítimo Almirante Barroso).

Em se tratando dos aspectos relacionados ao acesso aos meios de comunicação e à informação, identificou-se que $94,69 \%$ dos alunos têm acesso à internet (Figura 1) e destes que possuem acesso, $57 \%$ a utilizam de suas casas, conforme mostra a Figura 2.

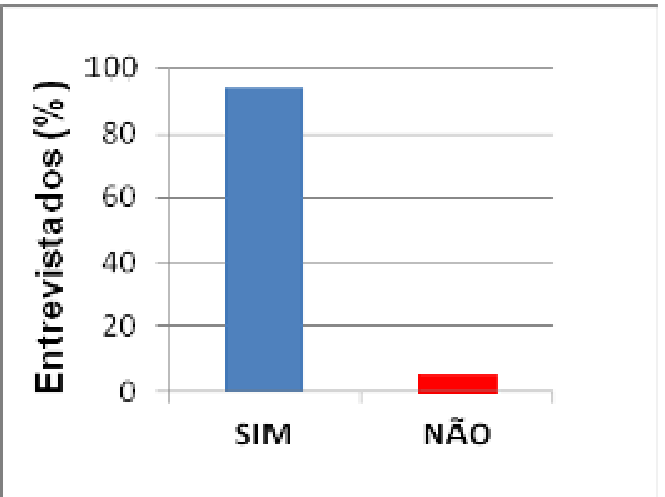

Figura 1: Acesso à internet (em \%)

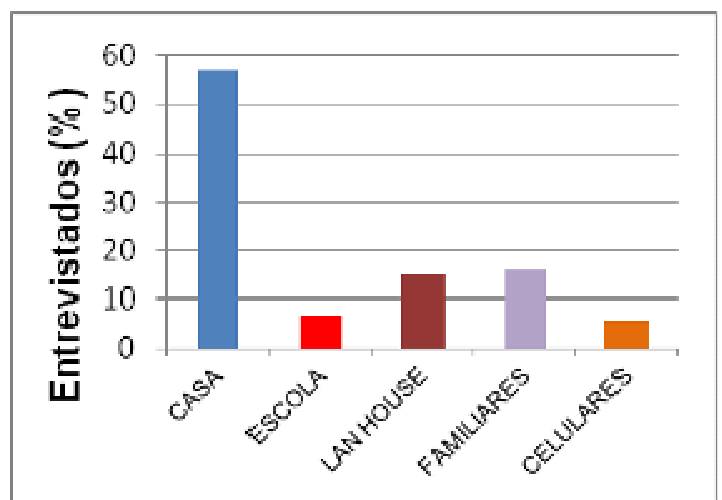

Figura 2: Locais maior acesso à internet (em \%)

Em relação aos programas de televisão, de acordo com a Figura 3, ficou evidente a baixa procura pelos temas jornais/educativos, desenhos e esportes, em detrimento de programas como novelas e programas de auditório que obtiveram $22 \%$ e $13 \%$ respectivamente. Os programas variados tiveram $27,45 \%$ das indicações. Sobre a leitura de jornais (Figura 4) a realidade também é de grande disparidade, na qual apenas 10\% afirmam ler regularmente. 


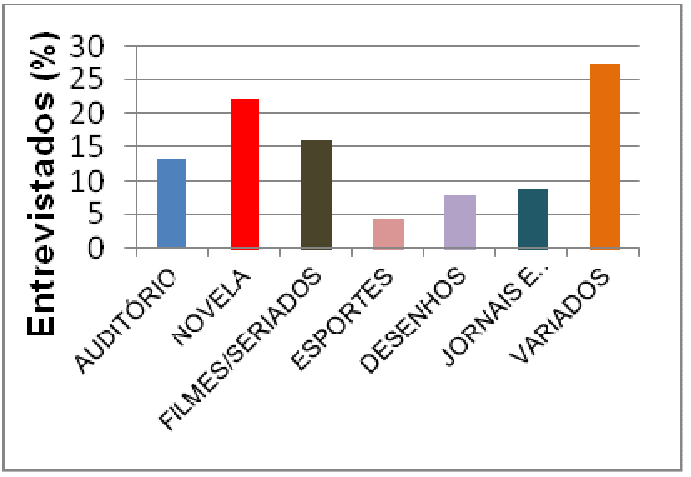

Figura 3:Programas de tv mais assistidos.

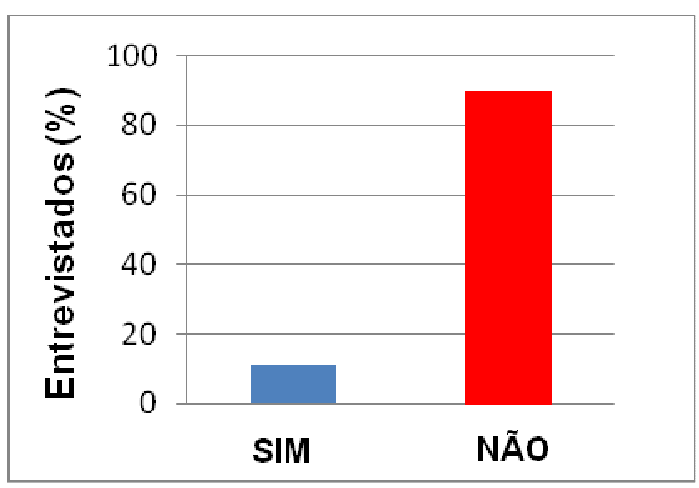

Figura 4: Percentual dos que lêem jornal.

Quanto a participação em atividades comunitárias, apenas $22 \%$ dos entrevistados aderem a algum tipo de atividade oferecida pelo centro cultural e comunitário do bairro. Em relação a religião, apenas $57 \%$ frequentam igreja, ilustrada na Figura 5 e destes $77 \%$ são evangélicos (Figura 6). Não teve participação de outra religião ou doutrina entre os entrevistados.

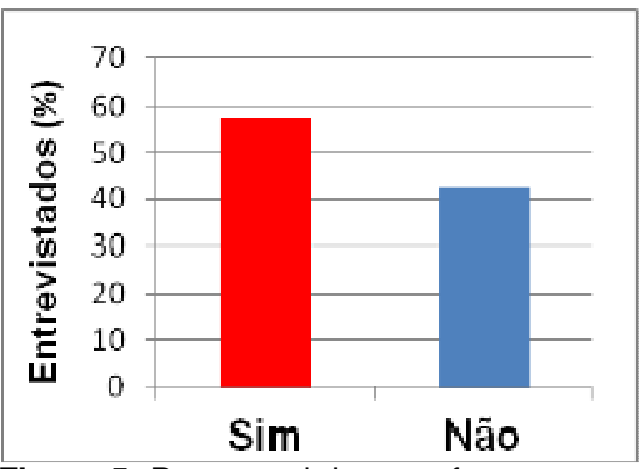

Figura 5: Percentual dos que frequentam igreja.

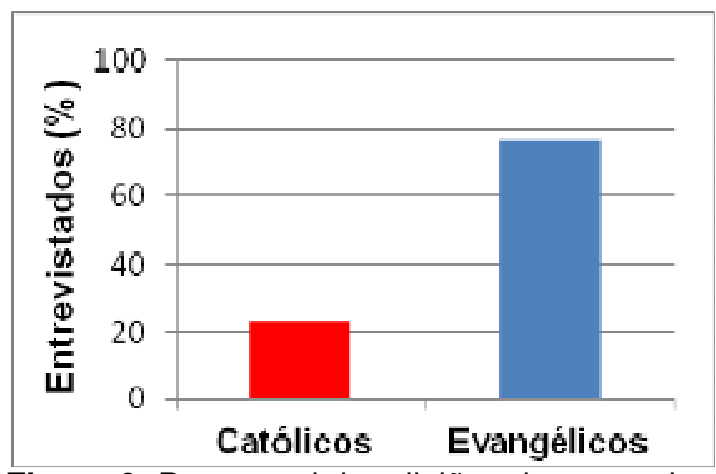

Figura 6: Percentual de religiões dos entrevistados que frenquentam igreja.

\section{Aspectos de infraestrutura e socioeconômicos}

Nessa temática, o objetivo foi de obter dados sobre renda familiar e comparar com a renda per capita do município, além de verificar o percentual das moradias de aluguel e ter informações sobre o tipo de moradia, uso e satisfação do transporte público e por fim reconhecer o percentual dos que têm acesso à energia elétrica.

Considerando o item renda familiar, cabe ressaltar que neste quesito, podem ocorrer vieses quanto à renda e este item foi respondido junto com a orientação dos responsáveis, na expectativa de gerar um dado mais próximo da realidade. Na Figura 7 visualiza-se a distribuição da renda no Morro do Algodão. 


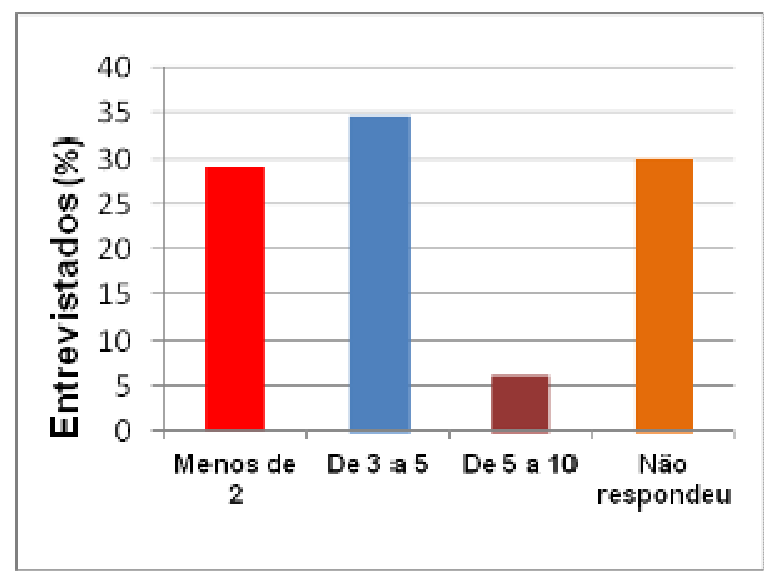

Figura 7: Percentual de renda familiar entre os entrevistados (em salário mínimo).

Para ter um parâmetro oficial de renda no município, utilizaram-se os dados do SEADE (Fundação Sistema Estadual de Análise de Dados) no qual mostra que em Caraguatatuba a renda per capita é de $R \$ 641,55$. Dos 113 entrevistados, cerca de $30 \%$ omitiram a renda. Das respostas, $34,51 \%$ afirmaram que sua renda familiar situa-se entre três e cinco salários mínimos, enquanto $29,2 \%$ afirmam ter uma renda inferior a dois salários mínimos. Uma pequena parcela de 6,19\% respondeu ter renda entre cinco e dez salários mínimos. Considerando de modo hipotético que estas famílias sejam formadas por três ou mais indivíduos, a renda familiar da população do bairro situa-se abaixo da média do município.

Analisando os dados de habitação (Figura 8), apenas 4,42\% moram em casas cedidas por terceiros sem o pagamento de aluguel. Destaca-se que $69,92 \%$ dos entrevistados moram em casa própria, enquanto $25,66 \%$ habitam em casas alugadas, comprometendo parte da renda familiar. Comparado com a pesquisa feita pelo Instituto Supereco (2011) no mesmo bairro, a situação habitacional continua semelhante, pois de acordo com o referido instituto, $70 \%$ dos entrevistados possuem casa própria, $24 \%$ são alugadas e $6 \%$ são habitações cedidas por terceiros.

Já em relação ao tipo de construção, a Figura 9 revela que 12,39\% dos entrevistados vivem em construções mistas (madeira e alvenaria). 


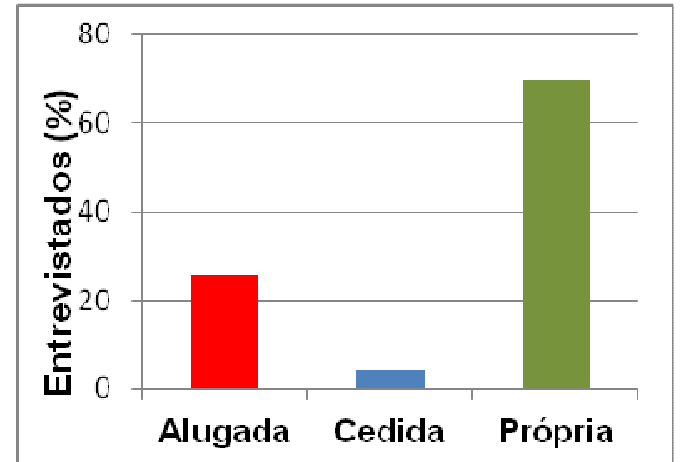

Figura 8: Forma de moradia (em \%).

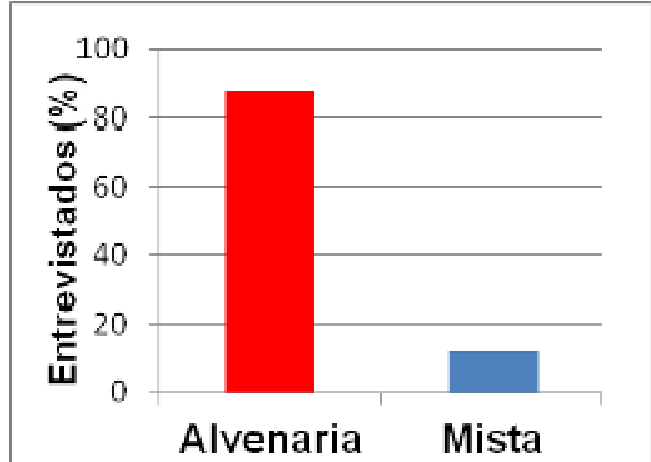

Figura 9: Tipo de construção da moradia (em \%)

A Figura 10 documenta a precariedade de habitação em área periférica do bairro, na qual revela a inexistência de infraestrutura urbana. Nesse trecho do bairro, as ruas ainda não estão demarcadas e como se pode observar, a rede de energia elétrica é clandestina. Neste caso, para se chegar até a habitação, é necessário atravessar o córrego, cuja função neste caso serve de despejo de esgoto, situação comum nessa parte do bairro, no qual os efluentes não são coletados, muito menos, tratado, sendo comum encontrá-lo a céu aberto.

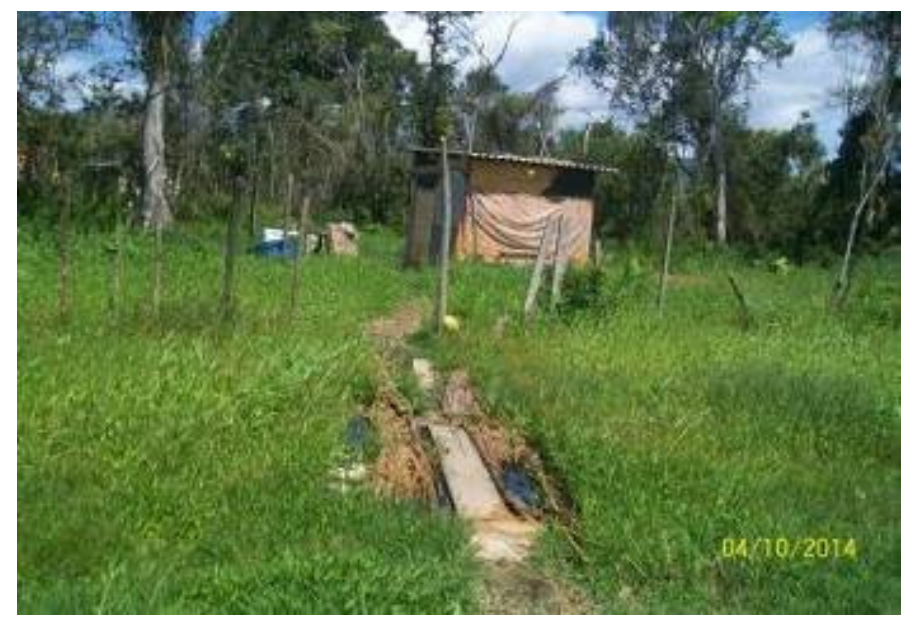

Figura 10: Aspecto de habitação precária e sem infraestrutura no Morro do Algodão. Fonte: Arquivo pessoal.

Considerando o item transporte, $55,75 \%$ dos entrevistados utilizam transporte público (Figura 11). Neste grupo, $79,37 \%$ responderam estarem insatisfeitos com horários, linhas e preços (Figura 12). Em relação ao transporte público, a cidade só possui uma empresa de ônibus e o custo da passagem no período da entrevista era $R \$ 3,20$. A linha que atende ao bairro liga-o somente ao centro da cidade e o tempo médio entre as saídas é de quarenta minutos. 


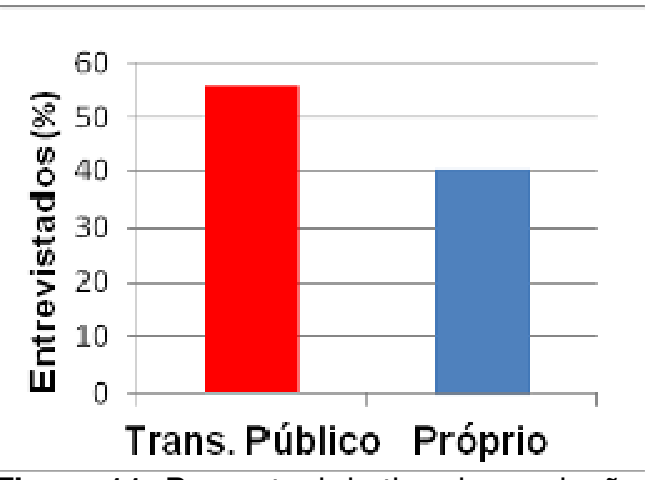

Figura 11: Percentual de tipo de condução entre os entrevistados.

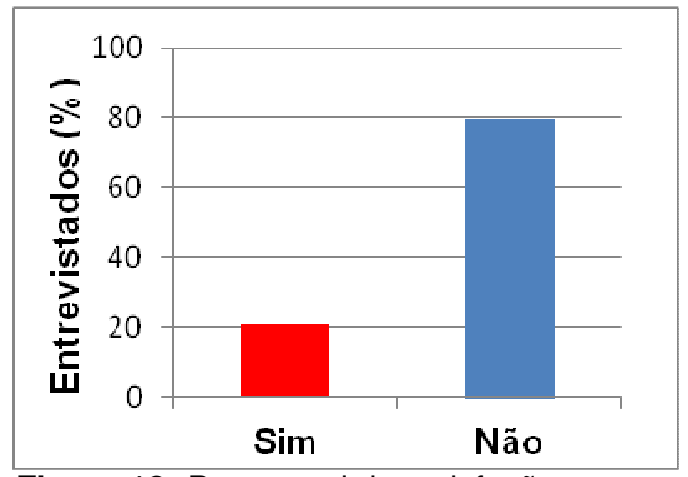

Figura 12: Percentual de satisfação com o transporte público.

Quanto à energia elétrica, $100 \%$ dos entrevistados disseram receber o serviço, porém, não foi possível obter dados confiáveis sobre esse tipo de ligação, quanto a sua formalidade.

\section{Saneamento/Meio Ambiente}

O conceito de saneamento ambiental para Dias (2004) é formado por água tratada, rede e tratamento de esgotos, rede de águas pluviais, coleta e tratamento de resíduos sólidos. Ele ainda identifica o grau de evolução de uma comunidade e a seriedade e competência de seus governantes pelos esforços em prol do saneamento, pois para este autor, não há saúde sem saneamento. Dentre as consequências da falta de saneamento, estão: a poluição do solo, da água (incluindo as subterrâneas), doenças, entre as quais diarreias, esquistossomose, hepatite, entre outras.

De acordo com Reani e Segalla (2006) um dos grandes desafios do saneamento no Brasil é atender as populações mais pobres, que se aglomeram em moradias precárias nas áreas mais afastadas da cidade, as quais carecem de infraestrutura e saneamento. Os autores enfatizam ainda que no Brasil, essa situação é agravada devido à grande desigualdade social existente e que se reflete nos aparatos de infraestrutura urbana.

No Brasil, o conceito de saneamento básico é regido pela Lei $\mathrm{n}^{0}$ $11.445 / 07$ que estabelece as diretrizes nacionais e no seu artigo $2^{\circ}$ destacamos os incisos:

I - a universalização do acesso;

II - a integralidade, compreendida como o conjunto de todas as atividades e componentes de cada um dos diversos serviços de saneamento básico, propiciando à população o acesso na conformidade de suas necessidades e maximizando a eficácia das ações e resultados; 
III - abastecimento de água, esgotamento sanitário, limpeza urbana e manejo dos resíduos sólidos realizados de formas adequadas à saúde pública e à proteção do meio ambiente.

Ao considerar a baixa cobertura do saneamento básico no Brasil e a legislação vigente, nota-se um grande abismo entre teoria e prática, inclusive no espaço de estudo desta pesquisa, no qual o bairro ainda não é atendido em sua totalidade na coleta de resíduos sólidos, coleta e tratamento de esgoto e disponibilidade do serviço de água canalizada.

No que tange à coleta de esgoto, observou-se uma deficiência no atendimento, pois nas casas da maioria dos entrevistados $(57,52 \%)$, o esgoto ainda não é coletado, que por sua vez, é armazenado em fossas sépticas ou lançado nos córregos e rios. Esse procedimento causa danos ambientais, como a contaminação das águas fluviais e subterrâneas. É válido lembrar que o bairro é margeado pelo rio Juqueriquerê, usado como lazer, fonte de alimento (pesca), além do uso da água pelas famílias mais pobres que não desfrutam do abastecimento formal de água. O índice do bairro se assemelha ao do município, que segundo a SEADE é de $57,94 \%$, porém, está muito aquém do índice estadual, que é de $89,75 \%$.

Na Figura 13, é nítida a desvantagem do percentual da coleta de esgoto no bairro, enquanto na Figura 14, o registro fotográfico do esgoto que corre a céu aberto, oferecendo riscos à população.

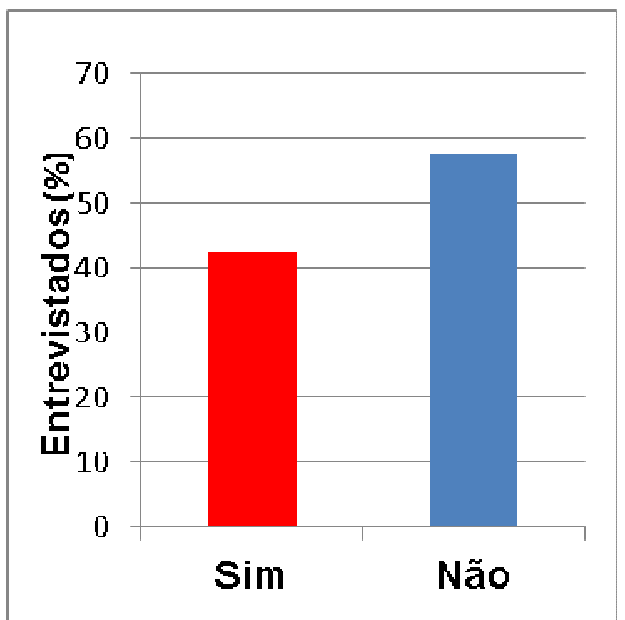

Figura 13: Percentual de coleta de esgoto entre os entrevistados.

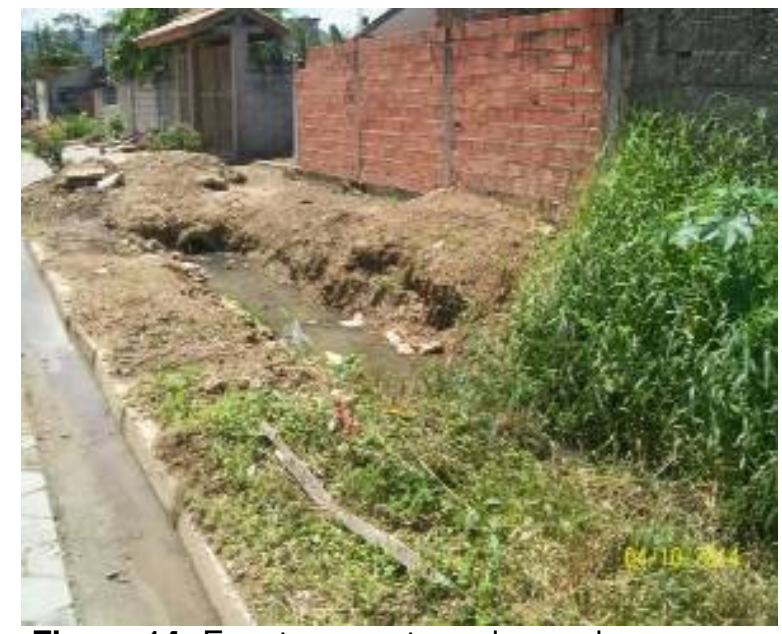

Figura 14: Esgoto exposto ao longo de ruas do bairro Morro do Algodão. Fonte: Arquivo pessoal.

No quesito água, o abastecimento é prestado pela empresa Sabesp (Companhia de Saneamento Básico do Estado de São Paulo), e, de acordo com a Figura 15, atende a $89 \%$ dos entrevistados, enquanto $6,5 \%$ dizem não 
receber este serviço, subentendendo-se que exista uma captação clandestina de água. Os outros $4,5 \%$ desconhecem a origem do abastecimento. A Fundação Seade atesta que no município o índice chega a 98,21\% dos domicílios.

Não saber a origem da água é preocupante e pode trazer riscos à população que a consome, como já destacados por Dias. O fato de não haver parâmetros e controle de qualidade, como ocorre com a Sabesp, potencializam os riscos, uma vez que já é sabido que uma pequena parcela consome água de poços ou de rio. Entre os entrevistados, mesmo àqueles que usufruem dos serviços de água canalizada, grande parcela (85,85\%) não utilizam nenhum tratamento adicional de desinfecção da água, conforme a Figura 16.

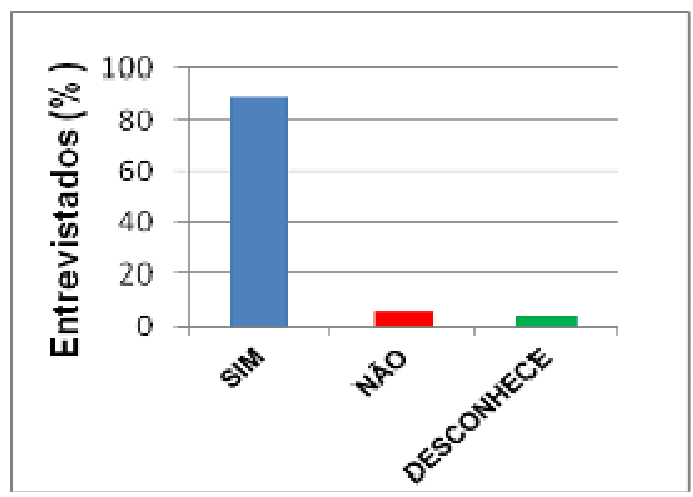

Figura 15: Percentual de residência ligada à rede de água

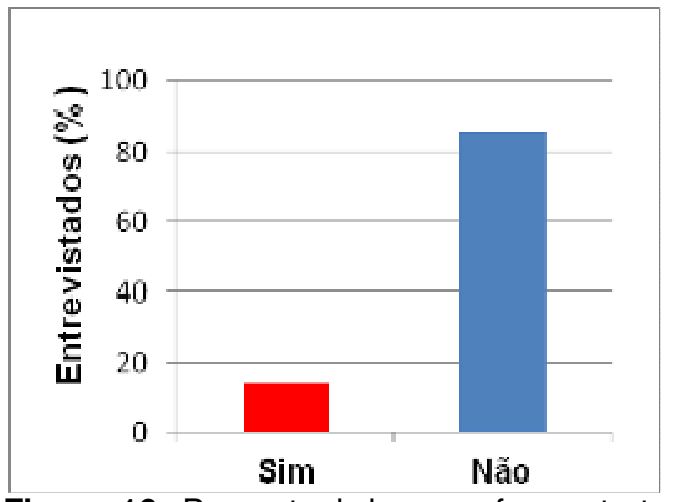

Figura 16: Percentual dos que fazem tratamento domiciliar de água, como filtrar ou ferver a água.

Num estudo comparável realizado na comunidade Vila Nova, em Joinville - SC, com situação socioeconômica semelhante ao do presente estudo, efetuado por Baldin et al. (2004), 55\% dos questionados não realizam nenhum tratamento adicional para desinfecção da água, aumentando assim os riscos de saúde e de contaminação por meio desta, portanto, são necessárias nos dois casos intervenções de órgãos competentes, principalmente na conscientização das famílias.

De acordo com Zancul (2006), a Organização Mundial de Saúde (OMS), calcula que 25 milhões de habitantes no mundo morrem a cada ano devido a doenças na qual a água é a principal transmissora, como cólera e diarreia. Desta maneira, o saneamento básico, já destacado por Dias (2006), possui papel fundamental na conservação ambiental e do bem-estar das populações. A existência desses serviços, quando prestados de maneira correta, contribui para promover e garantir as condições de vida e à saúde da população.

Em relação à coleta de lixo no bairro, representada na Figura 17, das famílias dos entrevistados, 92,04\% recebem este serviço, estando o bairro abaixo do índice para o município, que é de 99,79\%, segundo a Fundação Seade. Constatou-se, portanto, que um pequeno grupo está alijado de um 
importante serviço público, sendo a consequência disso à disposição inadequada do lixo doméstico, (como lançar no rio, apontado pela maioria daqueles que não tem o serviço de coleta, conforme a Figura 18) que acarreta prejuízos ambientais diversos, como contaminação dos rios, do solo e atração de animais sinantrópicos, que são vetores de diversas doenças, além da poluição visual. Todos esses problemas diminuem a qualidade de vida dessa população, que deve ser mapeada pelo Poder Público para que sejam tomadas as providências necessárias, de forma que essas pessoas usufruam dos serviços públicos a que tem direito.

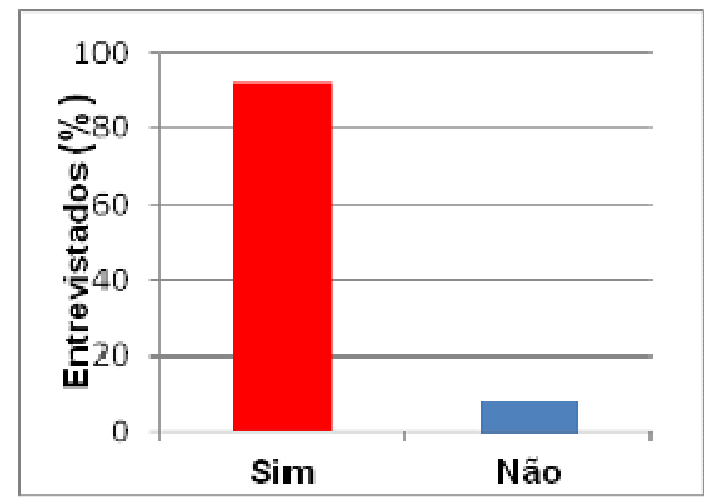

Figura 17: Percentual de coleta pública de lixo

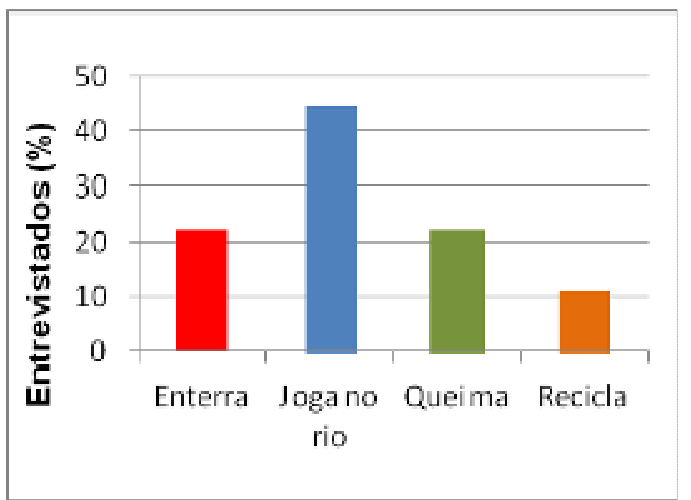

Figura 18: Destino do lixo na ausência da coleta pública.

O item a seguir objetivou identificar os principais problemas ambientais recorrentes na localidade e adjacências na percepção dos entrevistados. Este quesito do questionário enumerou 18 problemas ambientais, nos quais os entrevistados puderam marcar mais de uma alternativa. Foram enumeradas 370 indicações que permitiram, através de sua percepção, apontar os casos mais evidentes destes problemas. Estas indicações foram transformadas em porcentagem.

A Figura 19 apresenta a distribuição das respostas em porcentagens. Os itens mais percebidos pelos entrevistados como problemas ambientais foram: poluição das águas (15\%), enchentes (11\%), poluição do ar (10\%) e queimadas $(9,5 \%)$.

Apesar do item "enchentes" ter sido o segundo mais indicado, é provavelmente o que mais causa danos diretos à população, que sofre de modo recorrente no período mais chuvoso do ano, sejam pelas perdas materiais ou pelo desabrigo. Moura (2013) afirma que a "ocupação desordenada do espaço urbano e o manejo inadequado das atividades antrópicas acarretam problemas ambientais sérios às cidades sendo, portanto, essenciais à sociedade o uso de gestão adequada visando à diminuição do impacto social, ambiental e econômico provocados por enchentes e alagamentos". 


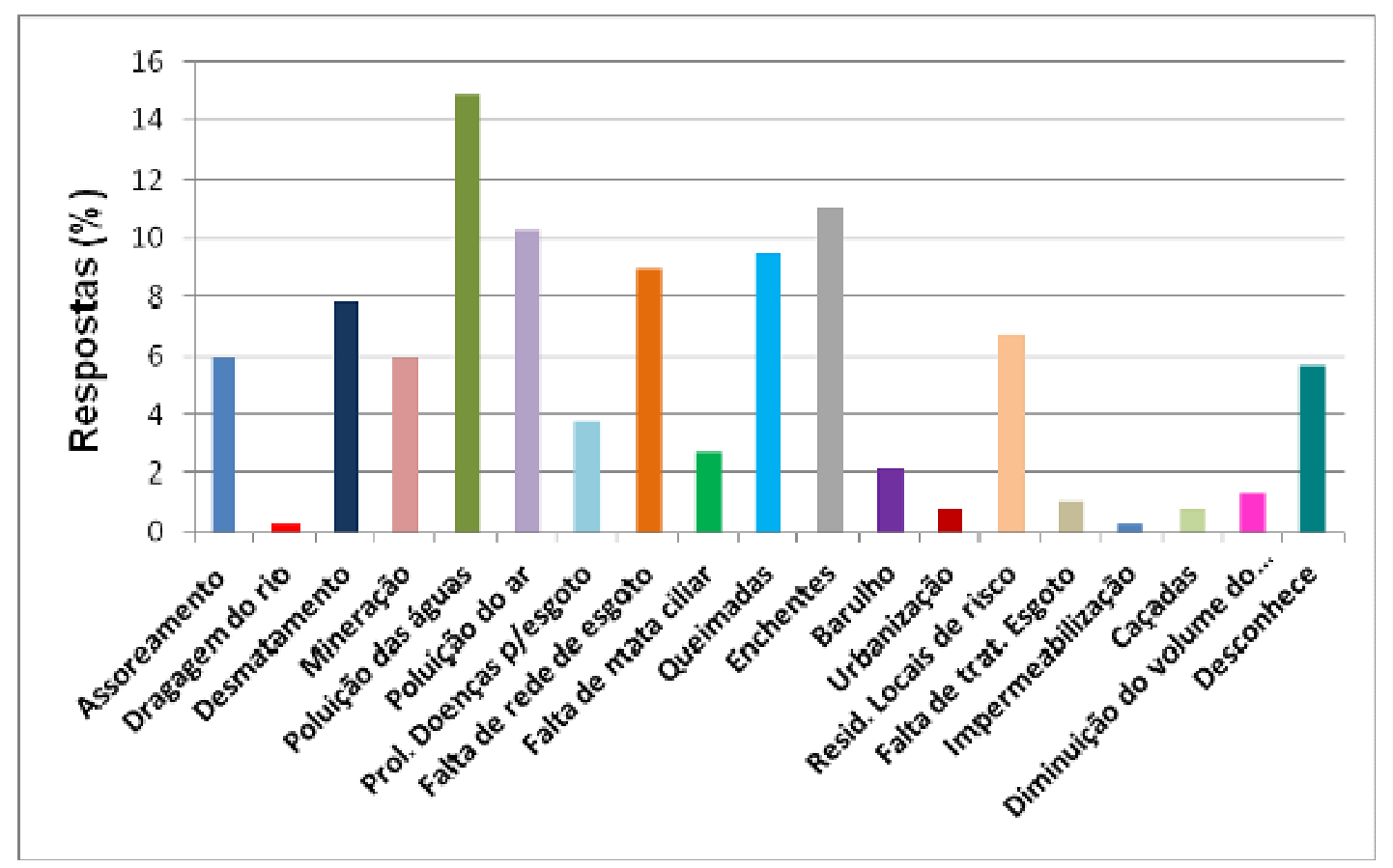

Figura 19: Percentual dos principais problemas ambientais percebidos pelos entrevistados.

O tema percepção dos problemas ambientais faz refletir que a partir de uma breve explicação e sistematização dos variados problemas ambientais abordados aos entrevistados, os mesmos conseguiram perceber problemas reais em diferentes graus. Sugere-se, portanto que esta temática seja aprofundada, principalmente no campo da educação ambiental, principalmente por ser a maneira mais eficaz da população cuidar do seu "habitat", compreendendo a sua importância, e, a partir daí, mudar seus valores e cobrar seus direitos junto aos representantes dos poderes municipal, estadual e federal.

\section{Considerações finais}

O questionário mostrou ser uma ferramenta eficaz na obtenção de dados no que tange aos aspectos socioeconômicos e ambientais no bairro em questão, e, a partir dai, permitir um diagnóstico das principais características da população que impactam diretamente na vida destes moradores e no seu ambiente.

O bairro possui grande parte de seus moradores oriundos de outras cidades e continua em intenso crescimento populacional e expansão urbana desordenada. Essa situação o coloca em demanda constante por investimentos do governo municipal para proporcionar maior inclusão social e melhorias de infraestrutura. Neste quesito, o saneamento básico pode ser apontado como um dos grandes desafios a ser vencido, pois a grande maioria 
da comunidade não tem acesso ao mesmo comprometendo sobremaneira a qualidade de vida da população.

Dentre os problemas ambientais mais evidenciados destacam-se a poluição das águas devido à falta do tratamento de efluentes e as enchentes, porém, outros problemas foram citados e necessitam de atenção, como o assoreamento do rio, desmatamento e queimadas, construção de residências em locais de risco, entre outros.

Esse trabalho buscou auxiliar a obtenção de dados socioeconômicos e ambientais do Bairro do Morro do Algodão no município de Caraguatatuba com vistas a entender sua realidade. Esse conhecimento é de grande importância para auxiliar o poder público na tomada de decisões com vistas a sanar os problemas daquela comunidade. Outros projetos que trabalhem a educação ambiental no âmbito da escola são importantes e necessários para mudar valores e conscientizar a sociedade sobre a importância da participação coletiva na resolução dos problemas a ela afeitos.

\section{Agradecimentos}

À Prefeitura Municipal de Caraguatatuba, por financiar a bolsa de estudo do Mestrado em Ciências Ambientais, pela Universidade Camilo Castelo Branco - UNICASTELO.

\section{Referências}

ALVES, A.O; LEAL, A.C. Pressupostos teóricos e metodológicos do planejamento ambiental. Formação. Presidente Prudente/SP: FCT/UNESP. v.1, n.10, p. 31-50, 2003.

BALDIN, $\mathrm{N}$, et al. Instrumento de pesquisa (questionário) em educação ambiental comunitária - elaboração e testagem: uma experiência na comunidade Vila Nova em Joinville/SC. Revista Saúde e Ambiente. JoinvilleSC, v.5, no2, p. 52-68, dez., 2004.

BRASIL. Lei no 11.445/07 - DIRETRIZES DO SANEAMENTO BÁSICO Disponível em $\quad<$ http://www.planalto.gov.br/ccivil 03/ ato20072010/2007/lei/l11445.htm>, Acesso em 01/10/2015.

DIAS, G.F. Ecopercepção: um resultado didático dos desafios socioambientais. São Paulo: Gaia, 2004.

DIAS, G.F. Atividades interdisciplinares de educação ambiental. 2.ed. São Paulo: Gaia, 2006.

GIGLIOTTI, C.M.C, SANTOS, M.J. A expansão urbana de Caraguatatuba (1950-2010): uma análise das transformações sócio espaciais. Caminhos de Geografia. Uberlândia, v.14, n.46, p. 150-159, jun., 2013. 
HUNKA, P.G. Diagnóstico socioambiental e dos usos dos recursos hídricos na bacia do rio Guajú PB/RN. 2006. 130 p. Dissertação (Mestrado em Geografia) - Programa de Pós Graduação em Geografia - UFPB, João Pessoa.

INSTITUTO SUPERECO - Diagnóstico socioambiental e sanitário dos bairros do porto novo, morro do algodão e barranco alto, município de Caraguatatuba, 2011. Documento gentilmente cedido pelo Instituto.

MOURA, C.A. Avaliação de tendência a enchentes das bacias hidrográficas do município de Caraguatatuba-SP. Revista de Geografia (UFPE), Recife, v.30, n.2, p. 123-138, set., 2013.

PANIZZA, A.C. Imagens orbitais e Coremas: uma proposta metodológica para o estudo da organização e dinâmica espacial, aplicação ao município de Ubatuba, Litoral Norte do Estado de São Paulo, Brasil. 2004. Tese (Doutorado em Geografia Física) - Faculdade de Filosofia, Letras e Ciências Humanas, Universidade de São Paulo, 2004. Disponível em $<$ http://www.teses.usp.br/teses/disponiveis/8/8135/tde-30092005-180603/ptbr.php> Acesso em: 25/09/2014.

REANI, R.T; SEGALLA, R. A Situação do esgotamento sanitário na ocupação periférica de baixa renda em áreas de mananciais: consequências ambientais no meio urbano. ANPPAS. UFSCAR, São Carlos: 2006.

SANTOS, M. A urbanização brasileira. 5.ed. São Paulo: Edusp, 2005.

SANTOS, R.F. Planejamento ambiental: teoria e prática. 2 ed. São Paulo: Oficina dos textos, 2009.

SÃO PAULO: Estado. SEADE, Fundação Sistema Estadual de Análise de dados. Informação dos Municípios Paulistas, 2011. Disponível em: $<$ www.seade.gov.br>. Acesso em: 28/09/2014

SOUZA, C. Políticas públicas: uma revisão da literatura. Revista Sociologias. Porto Alegre, ano 8, n.16, p. 20-45, jul/dez., 2006.

ZANCUL. M.S. Água e Saúde. Revista Eletrônica de Ciências. São Carlos, n.32, abril 2006. Disponível em $<$ http://www.cdcc.sc.usp.br/ciencia/artigos/art 32/atualidades.html>. Acesso em $01 / 09 / 2014$. 